\title{
A chromosome 1q22 microdeletion including $A S H 1 L$ is associated with intellectual disability in a Chinese family
}

Hui $\mathrm{Xi}^{1,2}$, Ying Peng ${ }^{1,2}$, Wanqin Xie ${ }^{1}$, Jialun Pang ${ }^{1,2}$, Na Ma ${ }^{1,2}$, Shuting Yang ${ }^{1,2}$, Jinping Peng ${ }^{3}$ and Hua Wang ${ }^{1,2^{*}}$

\begin{abstract}
Background: Copy number variants (CNVs) associated with developmental delay and intellectual disability (DD/ID) continue to be identified in patients. This article reports identification of a chromosome 1q22 microdeletion as the genetic cause in a Chinese family affected by ID.

Case presentation: The proband was a 19-year-old pregnant woman referred for genetic counseling and prenatal diagnosis at 18 weeks of gestation. She had severe ID with basically normal stature (height $154 \mathrm{~cm}$ [0 SD], weight $61 \mathrm{~kg}[-0.2 \mathrm{SD}]$, and head circumference $54 \mathrm{~cm}$ [-1.12 SD]). Her distinctive facial features included a prominent forehead; flat face; flat nasal bridge and a short upturned nose; thin lips; and small ears. The proband's father was reported to have low intelligence, whereas her mother was of normal intelligence but with scoliosis. Chromosome microarray analysis (CMA) reveals that the proband, her father and the fetus all carry a 1q22 microdeletion of 936.3 Kb (arr[GRCh37] 1q22 (155016052_155952375)×1), which was not observed in her mother and paternal grandparents and uncles, suggesting a de novo mutation in the proband's father. The microdeletion involves 24 OMIM genes including ASH1L (also known as KMT2H and encoding a histone lysine methyltransferase). Of note, haploinsufficiency of ASH1L has been shown to be associated with neurodevelopmental disorders. Based on the inheritance of the detected CNV in the pedigree and similar CNVs associated with ID in public databases (Decipher, DGV and ClinVar) and literature, the detected CNV is considered as pathogenic. The family chose to terminate the pregnancy.
\end{abstract}

Conclusions: The identified 1q22 microdeletion including ASH1L is pathogenic and associated with ID. This case broadens the spectrum of ID-related CNVs and may be useful as a reference for clinicians.

Keywords: Intellectual disability, 1q22, ASH1L, Microdeletion, Prenatal diagnosis

\footnotetext{
* Correspondence: wanghua213@aliyun.com

${ }^{1} \mathrm{NHC}$ Key Laboratory of Birth Defect for Research and Prevention, Hunan

Provincial Maternal and Child Health Care Hospital, Changsha, Hunan

Province, P. R. China

${ }^{2}$ The Prenatal Diagnosis Center of Hunan Province, Hunan Provincial

Maternal and Child Health Care Hospital, Changsha, Hunan Province, P. R.

China

Full list of author information is available at the end of the article
}

(C) The Author(s). 2020 Open Access This article is licensed under a Creative Commons Attribution 4.0 International License, which permits use, sharing, adaptation, distribution and reproduction in any medium or format, as long as you give appropriate credit to the original author(s) and the source, provide a link to the Creative Commons licence, and indicate if changes were made. The images or other third party material in this article are included in the article's Creative Commons licence, unless indicated otherwise in a credit line to the material. If material is not included in the article's Creative Commons licence and your intended use is not permitted by statutory regulation or exceeds the permitted use, you will need to obtain permission directly from the copyright holder. To view a copy of this licence, visit http://creativecommons.org/licenses/by/4.0/ The Creative Commons Public Domain Dedication waiver (http://creativecommons.org/publicdomain/zero/1.0/) applies to the data made available in this article, unless otherwise stated in a credit line to the data. 


\section{Background}

$\mathrm{DD} / \mathrm{ID}$ refers to a large group of developmental disorders characterized by significant limitations in intellectual functioning and adaptive behaviors [1]. The onset of DD/ID usually is observed before the age of 18 years. Patients at the age of 5 years or younger who present with reasoning and learning difficulties and motor developmental delay are diagnosed as DD, whereas those who become symptomatic at the age over 5 years are regarded as ID [2]. DD/ID, with an estimated incidence of $1-3 \%$, can be highly heterogeneous in clinical phenotype and genetic etiology [2]. About 25-50\% DD/ID is associated with genetic alteration, such as 21,18 , or 13 trisomy or submicroscopic deletion/duplication [3].

CMA is featured by whole genome coverage, high resolution and rapid detection [4]. It has been recommended as the first-line clinical diagnostic test for individuals with unexplained DD/ID, autism spectrum disorders (ASDs) or multiple congenital anomalies (MCA) [5]. CMA can not only detect submicroscopic chromosomal imbalances, but also delineate the size and gene content of the detected segment. This is crucial for phenotype/genotype correlation and for identifying candidate genes involved in the development of certain anomalies [6].

The present case documented the clinical phenotype and genetic analysis of a Chinese family affected by ID using CMA.

\section{Case presentation}

The proband was a 19-year-old pregnant woman who was referred to the department of medical genetics at the hospital for prenatal diagnosis due to a family history of intellectual disability. She was delivered vaginally at full-term. During the neonatal period, she was hypotonic and very passive. Her growth milestones were recalled. She walked at 1 year and 8 months of age, and learned to say "mama" at 2 years. She talked at nearly 3 years and showed severe ID. She began the first period of menstrual at the age of 13 years, and got married at 18 years. She was in pregnancy at 18 weeks' gestation when referred for genetic counseling and prenatal diagnosis. She had facial dysmorphism including a prominent forehead; flat face; flat nasal bridge and a short upturned nose; thin lips; and small ears (Fig. 1). Examinations in psychological clinic showed that her height was $154 \mathrm{~cm}$ [0 $\mathrm{SD}$ ]; weight was $61 \mathrm{~kg}$ [-0.2 SD]; and head circumference was $54 \mathrm{~cm}$ [-1.12 SD] [7, 8]. Her IQ score was 32 as accessed by the Wechsler Adult Intelligence ScaleRevised China (WAIS-RC). In terms of the scale, a score $\leq 75$ is considered as low intelligence, and a score of 32 suggests severe ID. Reportedly, she was able to care for herself in daily life. Clinical observation showed that she was introverted; seldom talked; had dementia and social dysfunction without depression and anxiety. Both her electroencephalogram (EEG) and brain MRI result were normal. No history of heart diseases was noted.

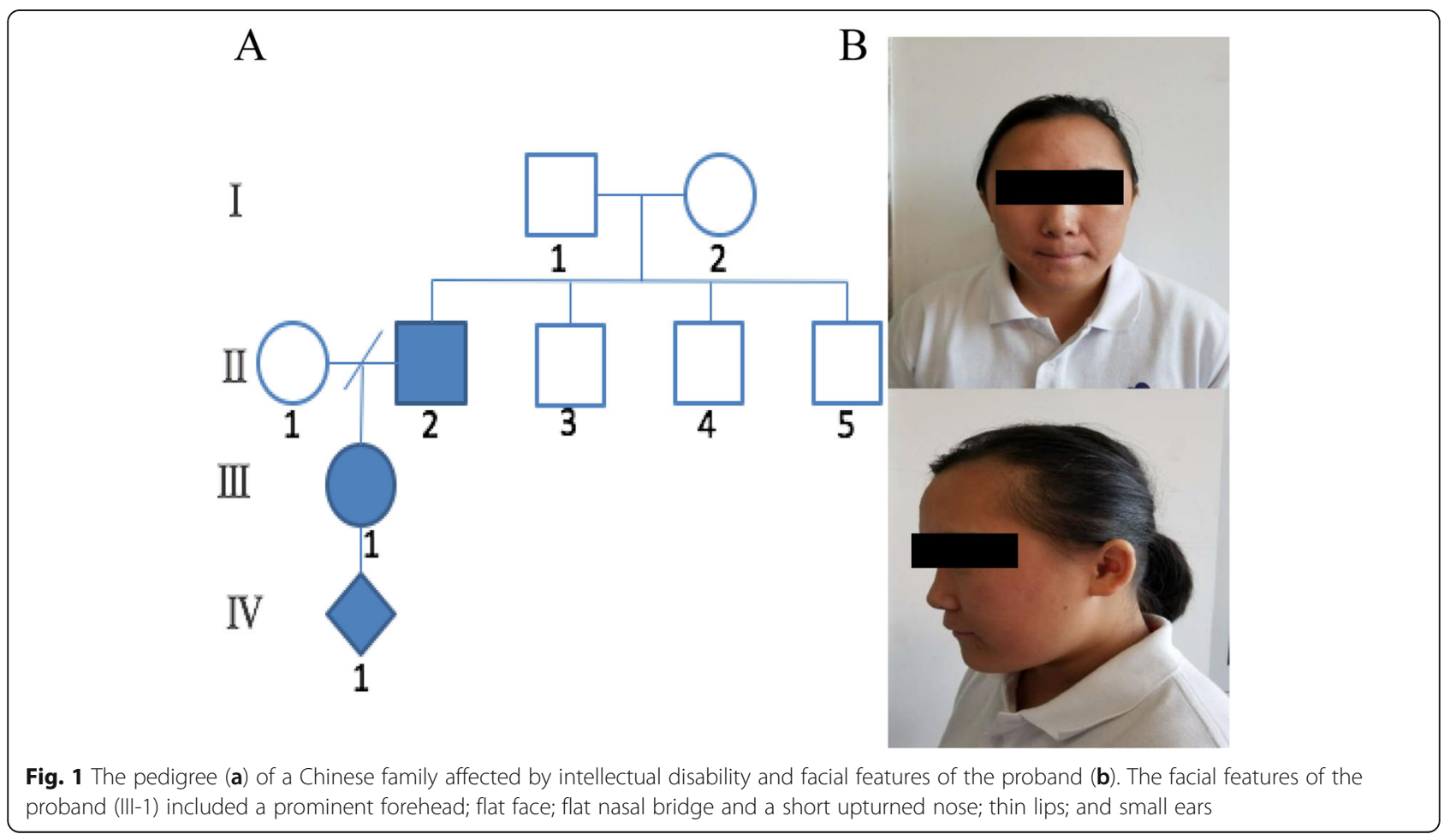


Her father was reported to have low intelligence, but an on-site examination for her father was not achieved. Her mother was of normal intelligence but had scoliosis. Her paternal grandparents and uncles and the fetus' father had no noticeable congenital anomalies.

Written informed consent was obtained from the family (The proband was under the guardianship of her mother). Peripheral blood for each participant and the amniotic fluid of the proband were drawn for genetic testing. Heart rate, blood pressure and electrocardiogram of the proband were monitored before amniocentesis. Conventional G-banded karyotype analysis showed a normal female karyotype $(46, \mathrm{XX})$ in the proband. However, CMA using the CytoScan $750 \mathrm{~K}$ Array from Affymetrix (Thermo Fisher Scientific, USA) revealed a $936.3 \mathrm{~kb}$ heterozygous deletion of chromosome 1q22 (arr[GRCh37] 1q22 (155016052_155952375)×1) in the proband (Fig. 2). The microdeletion was also detected in the proband's father (II-2) and the fetus (IV1 ), but absent in her mother (II-1), grandparents (I-1, I-
2) and paternal uncles (II-3, II-4). Other members within the pedigree were not tested. For all tested individuals, no other CNVs were detected except known polymorphisms (frequency $>1 \%$ ).

In search of public databases (Decipher, DGV and ClinVar) and literature, a few cases reported copy number losses of the 1q22 region including ASH1L and the associated phenotypes including ID with MCA (Table 1). Furthermore, haploinsufficiency of $A S H 1 L$ is strongly associated with DD/ID and MCA in multiple individual cases $[9,10]$. On the basis of these observations, plus the co-segregation of genotype and phenotype in the current case, the detected $\mathrm{CNV}$ is considered to be pathogenic, being in line with the guidelines from the American College of Medical Genetics (ACMG) [11]. After full consideration, the family chose to terminate the pregnancy.

\section{Discussion}

The identified microdeletion in the proband involves 43 known genes, of which 24 were OMIM genes, including

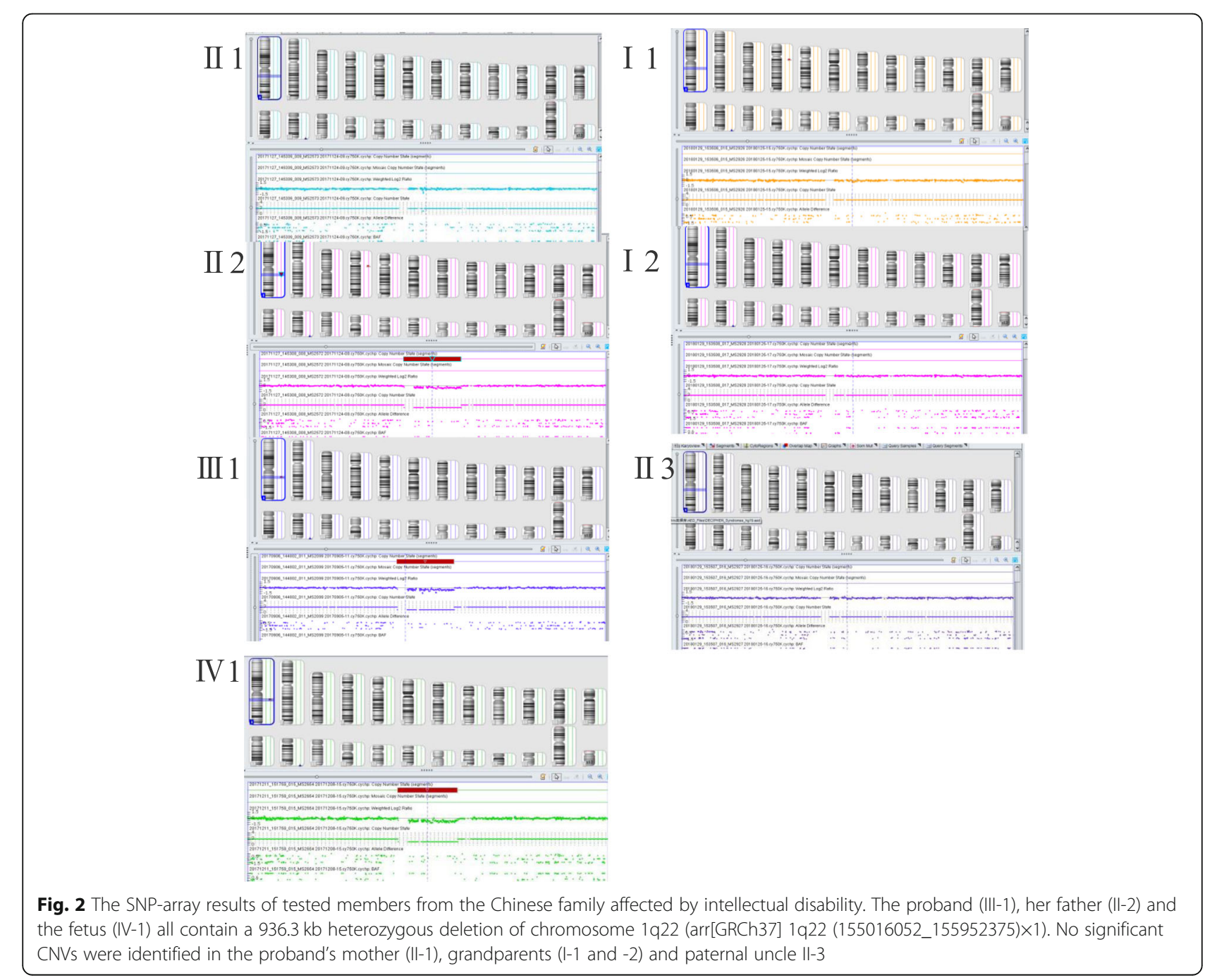


Table 1 1q22 microdeletions/duplications including ASH1L from public databases and literature

\begin{tabular}{|c|c|c|c|c|c|c|}
\hline $\begin{array}{l}\text { Database/ } \\
\text { Literature }\end{array}$ & Index ID & Variant & Size & Inheritance & Phenotype(s) & $\begin{array}{l}\text { Clinic } \\
\text { Significance }\end{array}$ \\
\hline This report & / & $\begin{array}{l}\text { [GRCh37] 1q22 (155016052 } \\
\text { _155952375)×1 }\end{array}$ & $936.3 \mathrm{~Kb}$ & Paternal & $\begin{array}{l}\text { Intellectual disability, behavioral } \\
\text { problems, forehead, flat face, flat } \\
\text { nasal bridge, short upturned nose, } \\
\text { thin lips, small ears. }\end{array}$ & Pathogenic \\
\hline Faundes et al. & / & 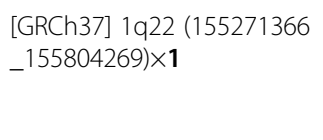 & $532.9 \mathrm{~Kb}$ & De novo & $\begin{array}{l}\text { Intellectual disability, behavioral } \\
\text { problems, cryptorchidism and } \\
\text { blocked nasolacrimal duct, } \\
\text { microcephaly, }\end{array}$ & / \\
\hline Decipher & 249,031 & $\begin{array}{l}\text { [GRCh37] 1q22 (154292095 } \\
-155569326) \times 1\end{array}$ & $1.28 \mathrm{Mb}$ & De novo & $\begin{array}{l}\text { Delayed speech and language } \\
\text { development, hypertelorism, } \\
\text { intellectual disability, long face, } \\
\text { low-set ears }\end{array}$ & Unknown \\
\hline Decipher & 255,240 & $\begin{array}{l}\text { [GRCh37] 1q22 (155192986 } \\
\left.{ }_{-} 156108069\right) \times \mathbf{1}\end{array}$ & $915.08 \mathrm{~Kb}$ & Unknown & $\begin{array}{l}\text { Broad nasal tip, delayed speech and } \\
\text { language development, dental } \\
\text { malocclusion, intellectual disability, } \\
\text { low-set ears, malar flattening, narrow } \\
\text { palate, nasal speech, posteriorly } \\
\text { rotated ears }\end{array}$ & Unknown \\
\hline Decipher & 359,103 & $\begin{array}{l}\text { [GRCh37] 1q22 (154687479 } \\
\left.\_156014014\right) \times 1\end{array}$ & $1.33 \mathrm{Mb}$ & De novo & $\begin{array}{l}\text { Abnormality of the nervous system, } \\
\text { autism, scoliosis }\end{array}$ & $\begin{array}{l}\text { Likely } \\
\text { pathogenic }\end{array}$ \\
\hline DGV & esv33869 & 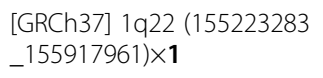 & $694.6 \mathrm{~Kb}$ & / & / & / \\
\hline DGV & dgv3n68 & $\begin{array}{l}\text { [GRCh37] 1q22 (155094978 } \\
\left.\_155313409\right) \times 1\end{array}$ & $218.4 \mathrm{~Kb}$ & / & / & / \\
\hline ClinVar & VCV000659609.1 & $\begin{array}{l}\text { [GRCh37] 1q22 (155294636 } \\
\text { _155452240)×1 }\end{array}$ & $157.6 \mathrm{~Kb}$ & / & / & Pathogenic \\
\hline Decipher & 251,442 & 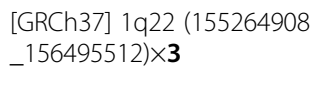 & $1.23 \mathrm{Mb}$ & Inherited & $\begin{array}{l}\text { Cryptorchidism, delayed speech } \\
\text { and language development, } \\
\text { intellectual disability, strabismus }\end{array}$ & Unknown \\
\hline ClinVar & VCV000253835.1 & $\begin{array}{l}\text { [GRCh37] 1q22 (155412745 } \\
\text { _155755215)×3 }\end{array}$ & 342.47 kb & / & $\begin{array}{l}\text { Attention deficit hyperactivity } \\
\text { disorder }\end{array}$ & Uncertain \\
\hline
\end{tabular}

Selected deletion/duplication cases are listed. "/", information not provided; "*", reference [9]

ADAM15 (OMIM: 605548), EFNA4 (OMIM: 601380), EFNA3 (OMIM: 601381), EFNA1 (OMIM: 191164), SLC50A1 (OMIM: 613683), DPM3 (OMIM: 605951), TRIM46 (OMIM: 600986), MUC1 (OMIM: 158340), THBS3 (OMIM: 188062), MTX1 (OMIM: 600605), GBA (OMIM: 606463), SCAMP3(OMIM: 606913), CLK2 (OMIM: 602989), HCN3(OMIM: 609973), PKLR (OMIM: 609712), FDPS (OMIM: 134629), ASH1L (OMIM: 607999), YY1AP1 (OMIM: 607860), DAP3 (OMIM: 602074), GON4L (OMIM: 610393), SYT11 (OMIM: 608741), RIT1 (OMIM: 609591), RXFP4 (OMIM: 609043), and ARHGEF2 (OMIM: 607560). Among these OMIM genes, TRIM46, CLK2, ASH1L, GON4L and ARHGEF2 are marked by a high probability of being loss of function intolerant ( $\mathrm{pLI} \geq 0.9$ ), in contrast to other genes with a moderate (RIT1 pLI: 0.67$)$ or low probability. Therefore, haploinsufficiency of the genes with high pLI is particularly concerned. In OMIM database, the phenotypes of heterozygous loss of TRIM46, CLK2, GON4L and ARHGEF2 in humans have not been fully documented, whereas a handful of individual patients featured by intellectual disability are reported to carry a heterozygous nonsense or frame-shift mutation of $A S H 1 L$, which results in truncated and nonfunctional protein [12-14]. The documented cases highly support that alteration in gene dosage of $A S H 1 L$ is associated with neurodevelopmental disorders. In more recent studies, additional de novo loss of function variants of ASH1L have been identified, and all patients presented with mild to severe DD/ID [10]. Interestingly, a $532.9 \mathrm{~kb}$ heterozygous deletion ( $\operatorname{arr}[\mathrm{GRCh} 37]$ 1q22 (155271366 155804269)×1) was found in a 7-year-old boy who had microcephaly and severe ID with MCA $[9,10]$. Notably, the microdeletion identified in the present case fully encompasses the $532.9 \mathrm{~kb}$ segment and involves more OMIM genes. Based on these observations, the $1 \mathrm{q} 22$ microdeletion of $936.3 \mathrm{~Kb}$ including $A S H 1 L$ is regarded as pathogenic and associated with ID. Importantly, not only micro-deletions, but also duplications within 1q22 may cause neurodevelopmental abnormalities (Table 1).

Though the pathogenicity of $A S H 1 L$ haploinsufficiency is evident, contribution of other OMIM genes (e.g. CLK2, ARHGEF2 and RIT1) to the phenotypes in this case cannot be fully excluded [15-17]. It is noteworthy 
that some clinical features of the proband resemble certain phenotypes such as broad forehead, broad nasal bridge, and learning/intellectual disabilities described in Noonan syndrome (NS), an autosomal-dominant disorder [15]. In a more recent report on the molecular and phenotypic spectrum of a Chinese NS cohort $(n=103), 6$ out of 7 patients with RIT1 mutation presented with various congenital heart defects, and a high rate (4 out of 7) of hypertrophic cardiomyopathy was observed in RIT1 mutation-positive patients [18]. With regard to the proband in this report, although cardiac imaging examination was not performed, heart rate, blood pressure and electrocardiogram were recorded prior to ultrasound-guided amniocentesis. The normal readouts plus no previous history of heart disease suggested that it was unlikely that the patient had cardiomyopathy. Taking the potential involvement of multiple functional genes into account, it remains to be further elucidated whether this 1q22 microdeletion causes contiguous gene syndrome.

ASH1L encodes a histone lysine methyltransferase that catalyzes mono- and di-methylation of histone 3 lysine 36 (H3K36). This gene is highly expressed in both embryonic and adult human brains [19]. An inadequate amount of ASH1L protein due to copy number loss of the gene may affect epigenetic regulation of the expression program involved in embryo and brain development. Animal model studies show that mice in homozygosity of a hypomorphic $A S H 1 L$ allele exhibited growth insufficiency, skeletal transformations and impaired fertility associated with developmental defects of reproductive organs [20]. In this case, the 1q22 microdeletion including $A S H 1 L$ resulted from a de novo mutation in the proband's father. Phenotipically, both the proband and her father were fertile, suggesting that haploinsufficiency of $A S H 1 L$ may not cause infertility in humans.

In summary, the present case shows the clinical phenotype of the proband in a Chinese family affected by ID and identification of a 1q22 microdeletion including ASH1L as the genetic cause in the pedigree. This case broadens the spectrum of ID-related CNVs and may be useful as a reference for clinicians. Apart from clinical findings, certain social and ethic issues also are brought into our sight by the case. For instance, was the pregnancy of the proband's own free will? How should the fate of the fetus be decided? Though it may take time to find out the best solutions for the scenario resembling the case, there is no doubt that more social care is demanded with regard to women patients with intellectual disability.

\section{Acknowledgements}

The authors sincerely thank the family for participation in the present study.

\section{Authors' contributions}

$H$. Xi and J. Peng recruited the patients. H. Xi and W. Xie wrote the manuscript. Y. Peng, S. Yang and J. Pang performed clinical analysis. J. Pang and N. Ma performed genetic tests. Hua Wang designed the study and analyzed the data. The author(s) read and approved the final manuscript.

\section{Funding}

This study was supported by grants (2015TP2029, 2017SK1030, 2019SK1010 and 2019SK1013) from Hunan Provincial Science and Technology

Department.

\section{Availability of data and materials}

The datasets used and/or analyzed during the current study are available from the corresponding author on reasonable request.

\section{Ethics approval and consent to participate}

Written informed consent was obtained from the participants for genetic tests. This study was approved by the Ethics Committee of Hunan Provincial Maternal and Child Health Care Hospital.

\section{Consent for publication}

Written informed consent was obtained for publication.

\section{Competing interests}

The authors declare that they have no competing interests.

\section{Author details}

${ }^{1} \mathrm{NHC}$ Key Laboratory of Birth Defect for Research and Prevention, Hunan Provincial Maternal and Child Health Care Hospital, Changsha, Hunan Province, P. R. China. ${ }^{2}$ The Prenatal Diagnosis Center of Hunan Province, Hunan Provincial Maternal and Child Health Care Hospital, Changsha, Hunan Province, P. R. China. ${ }^{3}$ Department of Medical Genetics, Maternal and Child Health Care Hospital of Shaoyang City, Shaoyang, Hunan Province, P. R. China.

Received: 3 January 2020 Accepted: 27 March 2020

Published online: 04 June 2020

\section{References}

1. Cappuccio G, Vitiello F, Casertano A, et al. New insights in the interpretation of array-CGH: autism spectrum disorder and positive family history for intellectual disability predict the detection of pathogenic variants. Ital J Pediatr. 2016;42:39.

2. Vasudevan P, Suri M. A clinical approach to developmental delay and intellectual disability. Clin Med (Lond). 2017;17(6):558-61.

3. Srour M, Shevell M. Genetics and the investigation of developmental delay/ intellectual disability. Arch Dis Child. 2014;99(4):386-9.

4. Levy B, Wapner R. Prenatal diagnosis by chromosomal microarray analysis. Fertil Steril. 2018;109(2):201-12.

5. Miller DT, Adam MP, Aradhya S, et al. Consensus statement: chromosomal microarray is a first-tier clinical diagnostic test for individuals with developmental disabilities or congenital anomalies. Am J Hum Genet. 2010; 86(5):749-64.

6. Kaminsky EB, Kaul V, Paschall J, et al. An evidence-based approach to establish the functional and clinical significance of copy number variants in intellectual and developmental disabilities. Genet Med. 2011;13(9):777-84.

7. Li Y, Zheng L, Xi H, et al. Stature of Han Chinese dialect groups: a most recent survey. Sci Bull. 2015;60(5):565-9.

8. Li Y, Zheng L, Yu K, et al. Variation of head and facial morphological characteristics with increased age of Han in southern China. Chin Sci Bull. 2013;58(4):517-24

9. Faundes V, Newman WG, Bernardini L, et al. Histone lysine Methylases and Demethylases in the landscape of human developmental disorders. Am J Hum Genet. 2018;102(1):175-87.

10. Shen W, Krautscheid P, Rutz AM, Bayrak-Toydemir P, Dugan SL. De novo loss-of-function variants of $\mathrm{ASH} 1 \mathrm{~L}$ are associated with an emergent neurodevelopmental disorder. Eur J Med Genet. 2019;62(1):55-60.

11. Kearney HM, Thorland EC, Brown KK, Quintero-Rivera F, South ST. American College of Medical Genetics standards and guidelines for interpretation and reporting of postnatal constitutional copy number variants. Genet Med. 2011;13(7):680-5.

12. de Ligt J, Willemsen MH, van Bon BW, et al. Diagnostic exome sequencing in persons with severe intellectual disability. N Engl J Med. 2012;367(20): 1921-9. 
13. Okamoto N, Miya F, Tsunoda T, et al. Novel MCA/ID syndrome with ASH1L mutation. Am J Med Genet A. 2017;173(6):1644-8.

14. Stessman HA, Xiong B, Coe BP, et al. Targeted sequencing identifies 91 neurodevelopmental-disorder risk genes with autism and developmentaldisability biases. Nat Genet. 2017;49(4):515-26.

15. Kouz K, Lissewski C. Genotype and phenotype in patients with Noonan syndrome and a RIT1 mutation. Genet Med. 2016;18(12):1226-34.

16. Nothwang $\mathrm{HG}$, Kim HG, Aoki J, et al. Functional hemizygosity of PAFAH1B3 due to a PAFAH1B3-CLK2 fusion gene in a female with mental retardation, ataxia and atrophy of the brain. Hum Mol Genet. 2001;10(8):797-806.

17. Ravindran E, Hu H, Yuzwa SA, Hernandez-Miranda LR, Kraemer N. Homozygous ARHGEF2 mutation causes intellectual disability and midbrainhindbrain malformation. PLoS Genet. 2017;13(4):e1006746.

18. Li X, Yao R, Tan X, et al. Molecular and phenotypic spectrum of Noonan syndrome in Chinese patients. Clin Genet. 2019:96(4):290-9.

19. Miller JA, Ding SL, Sunkin SM, et al. Transcriptional landscape of the prenatal human brain. Nature. 2014:508(7495):199-206.

20. Brinkmeier ML, Geister KA, Jones M, Waqas M, Maillard I, Camper SA. The histone methyltransferase gene absent, small, or homeotic Discs-1 like is required for Normal Hox gene expression and fertility in mice. Biol Reprod. 2015;93(5):121.

\section{Publisher's Note}

Springer Nature remains neutral with regard to jurisdictional claims in published maps and institutional affiliations.

Ready to submit your research? Choose BMC and benefit from:

- fast, convenient online submission

- thorough peer review by experienced researchers in your field

- rapid publication on acceptance

- support for research data, including large and complex data types

- gold Open Access which fosters wider collaboration and increased citations

- maximum visibility for your research: over $100 \mathrm{M}$ website views per year

At $\mathrm{BMC}$, research is always in progress.

Learn more biomedcentral.com/submissions 